\title{
O CENTRO HISTÓRICO DE DUBLIM (IRLANDA) E A EXPERIÊNCIA DE REABILITAÇÃO DE TEMPLE BAR
}

\author{
EduARdo Brito HenRIQues ${ }^{1}$
}

\begin{abstract}
Resumo - Temple Bar, um dos bairros tradicionalmente mais populares do centro histórico de Dublim, vivia nos anos 70 e 80 problemas graves de despovoamento e de profunda desqualificação social, funcional e paisagística. A operação de reabilitação desenvolvida nos anos 90 viria a ser uma das experiências do seu género mais bem sucedidas em toda a Europa. Em pouco mais de uma década, foi possível recuperar população, trazer novas funções para o bairro, criar emprego e valorizar o ambiente urbano, a partir de uma estratégia que em grande medida se baseou no desenvolvimento da fileira da cultura.
\end{abstract}

Palavras-chave: Centros históricos, reabilitação urbana, revitalização urbana, 'bairros culturais', Temple Bar, Dublim.

Abstract - The Dublin historic CITY CENTRE AND THE EXPERIENCE of TEMPLE BAR'S REHABILITATION: The aim of this paper is to present the experience of Temple Bar's rehabilitation in Dublin. As one of the most popular neighbourhoods in Dublin's historical city centre, Temple Bar has in the past undergone severe population decline coupled with a profound social, functional and environmental crisis. However, in the 1990s, one of Europe's greatest urban rehabilitation success stories was to begin in Temple Bar. Within about a decade, it was able to draw residents once again, attract new activities, bring employment back and enhance Temple Bar's urban environment. The culture cluster has played a truly innovative role in the strategy that was followed.

Key words: Historic city centres, urban rehabilitation, urban revitalisation, cultural neighbourhoods, Temple Bar, Dublin.

Résumé - LA RÉHABILITATION DU QUARTIER DE TEMPLE BAR DANS LE CENTRE HISTORIQue DE Dublin (IRLANDE). Temple Bar, un des anciens quartiers les plus populaires de Dublin, a connu de graves problèmes de dépeuplement et de régression sociale dans les années 70 et 80 du siècle passé. L'entreprise de réhabilitation menée à bien au cours des années 90 est une des plus réussies au niveau européen. En un peu plus de 10 ans, la population s'est remise à augmenter, de nouvelles fonctions sont apparues, des emplois ont été créés et les conditions de vie ont été améliorées, grâce à une stratégie basée en grande partie sur le développement culturel.

1 Geógrafo. Professor Auxiliar da Faculdade de Letras e Investigador do Centro de Estudos Geográficos, Universidade de Lisboa. E-mail: eduardo.b.h@fl.ul.pt 
Mots-clés: Centres historiques, réhabilitation urbaine, revitalisation urbaine, quartiers culturels, Temple Bar, Dublin.

\section{INTRODUÇÃO}

A reabilitação de bairros históricos, entendida nas suas múltiplas componentes - arquitectónica, urbanística e funcional -, constitui hoje um aspecto essencial das políticas urbanas. Como muitos têm observado (CHOAY, 1992; LARKHAM, 1996; TIESDALl et al., 1996 e ORBAȘLI, 2000), a reabilitação representa para o urbanismo pós-moderno o que a renovação urbana, normalmente associada a operações de slum clearance, e a programação e construção de 'cidades novas', representaram, no passado, para o urbanismo moderno. Raras são, com efeito, as cidades que nos nossos dias não manifestam preocupação com a conservação e (re)valorização das áreas históricas urbanas, e que com esse intuito não colocaram já em marcha acções ou medidas de política concretas.

É sabido que esta preferência pela conservação e revitalização urbana resulta em grande medida da decepção que, a partir de finais dos anos 60, as soluções preconizadas pelo urbanismo moderno começaram a suscitar, quer entre especialistas, quer na sociedade em geral. Em face do fracasso das 'cidades novas' e da manifesta insatisfação das populações relativamente às soluções do urbanismo moderno, a cidade tradicional, com a sua morfologia e a sua mistura de usos, voltou a ser tida como o paradigma da 'boa forma urbana' e, logo, como modelo a seguir. Tal como nas novas urbanizações se regressou então a essa antiga fórmula, retomando-se o conceito da rua, atenção redobrada passou a ser igualmente dispensada à cidade histórica.

Inscrita na mesma sensibilidade pós-moderna, invocam-se também cada vez mais razões de memória para defender a opção pela conservação e revitalização das áreas históricas das cidades. Argumenta-se com a necessidade de salvaguardar os elementos da identidade colectiva que conferem consistência e continuidade às comunidades humanas e ao sentido de lugar. Mas outras razões, mais práticas, podem ser igualmente adiantadas. A reabilitação de áreas urbanas históricas é muitas vezes justificada pela urgência de encontrar alternativas, designadamente no turismo, para a desindustrialização das cidades, assim como de descobrir soluções que contrariem ou invertam a tendência de dispersão urbana, com todas as suas consequências na ocupação desordenada do território, e favoreçam o retorno ao modelo da cidade compacta, que hoje de novo se reconhece ideal (URBAN TASK ForCe, 1999).

Apesar do consenso que se estabeleceu, entre técnicos e na população em geral, a propósito das vantagens da reabilitação urbana, não há certezas quanto ao modelo de intervenção mais indicado. Mesmo no plano doutrinário se defende hoje que as respostas devem ser necessariamente flexíveis e ajustadas, evitando a tentação de reproduzir mecanicamente pretensas soluções universais e procurando em vez disso adequá-las tanto aos problemas a que é necessário fazer face, como às potencialidades de regeneração de cada local (Brito Henriques, 2003). Será assim especialmente útil olhar para os casos bem sucedidos de reabilitação urbana e procurar aprender com eles, retendo o que possa ser aplicável a novas situações. Dublim é um desses casos.

\section{A EVOLUÇÃO DE DUBLIM E O SEU CENTRO HISTÓRICO}

Dublim, capital da República da Irlanda, situa-se na costa oriental da ilha, numa posição central, sensivelmente a meia distância entre os extremos norte e sul, em redor 
de uma larga baía formada pelo estuário do Liffey. Não sendo no quadro europeu uma grande metrópole, constitui, no respectivo território nacional, que até não há muito tempo manteve fortes características rurais (11\% do emprego na agricultura ainda em 1997 e mais de 40\% em meados do século XX), a principal polarização urbana: a população, que na cidade propriamente dita (o território do Dublin City Council) não chega a meio milhão de indivíduos, sobe para cerca de 1,1 milhões no conjunto da área metropolitana - administrativamente, o condado de Dublim (Dublin County) -, valor que equivale a cerca de $29 \%$ dos habitantes do país.

Por comparação com outras cidades europeias, nomeadamente da Europa continental, Dublim teve uma fundação tardia. O primeiro povoado permanente surgiu por meados do século IX, quando os marinheiros viquingues, vindos do Mar do Norte, depois de algumas décadas de incursões fugazes nas costas setentrional e ocidental da ilha, tomaram a parte oriental, frente ao Mar da Irlanda, fundando colónias estáveis. A mais importante estabelecer-se-ia no calmo estuário do Liffey, perto da desembocadura de um pequeno afluente - o Poddle - e na encosta de uma suave colina de onde facilmente se podiam dominar as praias; dela viria a evoluir Dublim.

Ao longo do período de ocupação nórdica, esse assentamento situado no promontório entre os dois cursos de água, a oeste da actual Parliament Street, sensivelmente entre a Essex Street West e o Castelo (GowEN, 1996), foi prosperando, persistindo como a principal base militar viquingue e um dos mais importantes portos comerciais das ilhas britânicas. Mesmo quando o domínio dos marinheiros noruegueses começou a declinar, por meados do século X, Dublim resistiu ainda por alguns decénios como um bastião viquingue, conseguindo manter até à batalha de Clontarf, em 1014, a sua independência face ao poder irlandês, então repartido por um grande número de pequenos reinos comandados por dinastias beligerantes.

O domínio inglês, a partir de 1170, trouxe novas oportunidades de desenvolvimento a Dublim. Depois da tomada militar, os invasores anglo-normandos procuraram consolidar a sua presença na Irlanda, estimulando a vinda de colonos para a ilha. A mão-de-obra aumentou. Com ela, vieram da Grã-Bretanha também novos produtos, técnicas e capitais, tudo isso concorrendo para que se vivesse então um período de crescimento económico rápido, de tal modo, aliás, que muitos historiadores não hesitam em considerar que «In all its history Ireland has never experienced an economic boom quite like that of the 13th century» (DufFy, ed., 2000: 38).

O surto económico do século XIII reflectiu-se no povoamento. A ocupação do campo pelos agricultores ingleses fez surgir, um pouco por toda a ilha, novos assentamentos humanos. O comércio e a vida de relação induziram, por sua vez, o florescimento de velhos povoados, como Dublim, que terá sido de todos o que então maior desenvolvimento atingiu.

Dando seguimento a uma vocação histórica da cidade na articulação do território insular com o espaço exterior ultramarino, que fora iniciada no período viquingue, Dublim é escolhida para sede do governo inglês na Irlanda. A cidade viveria na sequência disso um período de crescimento notável, especialmente intenso até à segunda década do século XIV, altura em que as invasões escocesas (1315-18), e pouco depois a peste negra (1348-49), instalam na Irlanda a crise e fazem eclodir movimentos de insurreição gaélicos que ameaçam e diminuem o poderio da aristocracia inglesa. No fim da Idade Média, a cidade de Dublim ocupava já toda a área situada a montante do esteiro do Poddle (onde hoje fica a Parliament Street) até à actual St. Augustine Street, e desde o Liffey ao Castelo (fig. 1). A norte da Christ Church, uma frente de muralhas interna separava a 'cidade alta' da parte baixa, que entretanto fora erguida sobre aterros. Uma 
cintura de muralhas completa, mais larga, delimitava depois a cidade exteriormente, cingindo no seu seio um casario denso e compacto.

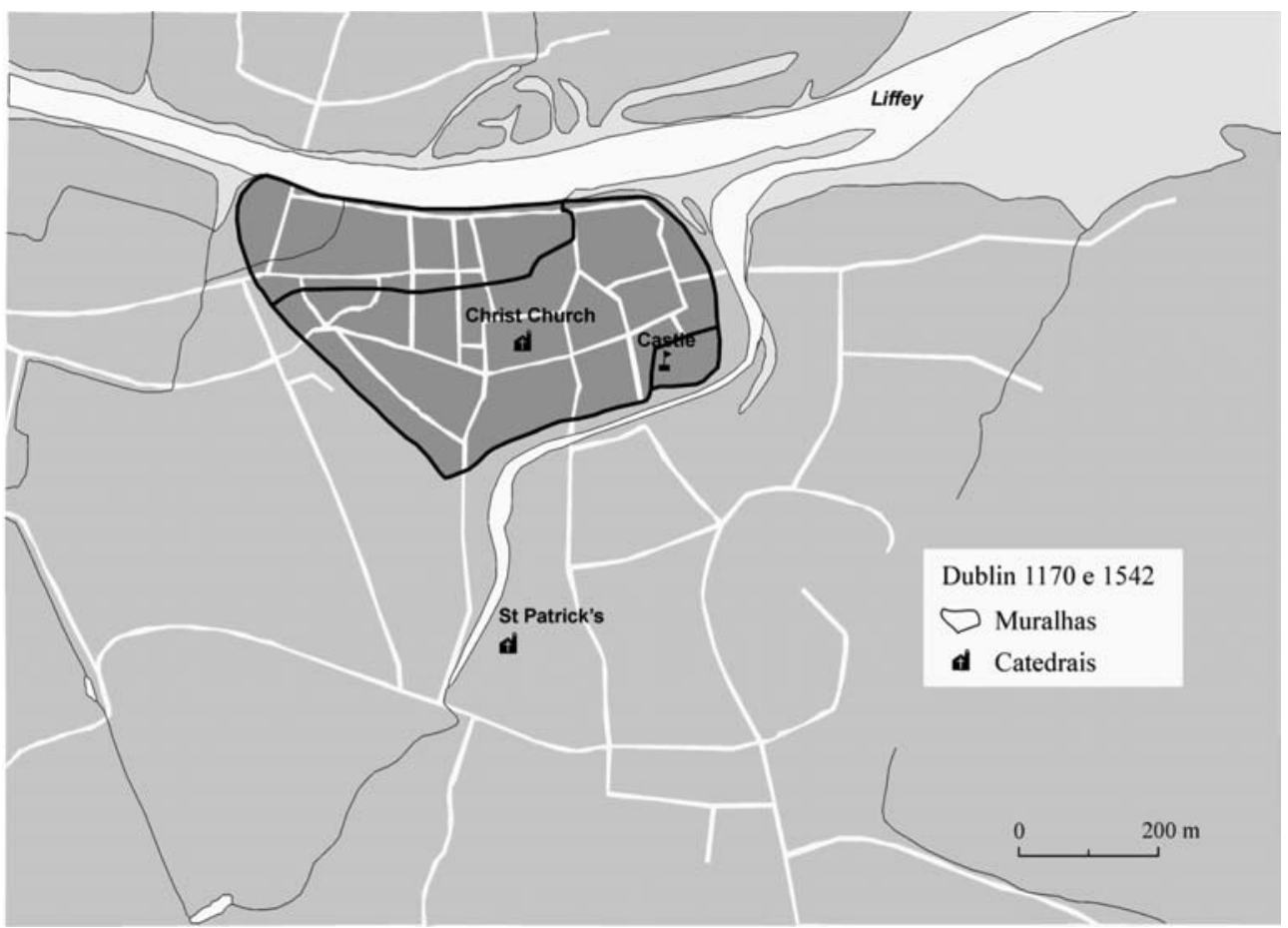

Fig. 1 - A cidade de Dublim na Idade Média

Fig. 1 - Dublin in the Middle Age

Fonte: adaptado de DuFry (2000)

Dessa Dublim medieval sobreviveu muito pouco. As construções, na sua maioria utilizando a madeira como elemento resistente, perderam-se. A própria malha urbana seria entretanto muito modificada. A catedral gótica (Christ Church) e o Castelo - este último, mantendo já pouquíssimo do seu aspecto original-constituem os dois mais importantes vestígios dessa época. St. Audoen's Church é, ainda no interior da cidade muralhada, um outro exemplo, se bem que mais tardio. Já fora de portas, resta como principal testemunho a St. Patrick's Cathedral.

Os séculos XVI e XVII, ainda que tendo sido globalmente marcados por grande instabilidade política (disputas dinásticas na Inglaterra; oposição entre anglicanos, católicos e protestantes puritanos; confrontos entre defensores do parlamentarismo e do absolutismo; insurreições cíclicas dos nobres irlandeses contra a coroa e a aristocracia inglesas, que responderam sempre violentamente;...), não deixaram de ter efeitos positivos em Dublim. Com a elevação da Irlanda ao estatuto de reino por Henrique VIII, passa a residir na capital irlandesa, junto do vice-rei nomeado pelo monarca inglês, uma 
pequena corte de altos funcionários encarregues dos negócios de estado. Em 1592, sob Isabel I, funda-se o Trinity College. Unida à coroa inglesa, Dublim acabaria por beneficiar da afirmação da Inglaterra entre as potências marítimas europeias, ganhando com o avanço da colonização da América e a intensificação dos fluxos de pessoas e mercadorias no Atlântico Norte.

Foi no decurso deste período, e em particular no século XVII, que Dublim se dilatou para a margem esquerda do Liffey e cresceu para jusante do esteiro do Poddle (fig. 2). As praias e os terrenos pantanosos da beira rio foram drenados. Diques destinados à regularização das margens e à melhoria das condições do porto permitiram conquistar, dos dois lados do Liffey, novos terrenos para urbanizar, neles se estabelecendo bairros populares destinados aos grupos profissionais que se expandiam e prosperavam com o crescendo da actividade portuária: marinheiros, mercadores e artesãos. Foi esse o caso de Temple Bar, desenvolvido sobre um extenso aterro na desembocadura do Poddle e ao longo das praias do Liffey, em direcção ao Trinity College; a sua planta, de ruas regulares, obedientes a uma ortogonalidade algo grosseira, pouco erudita, atesta essa origem.

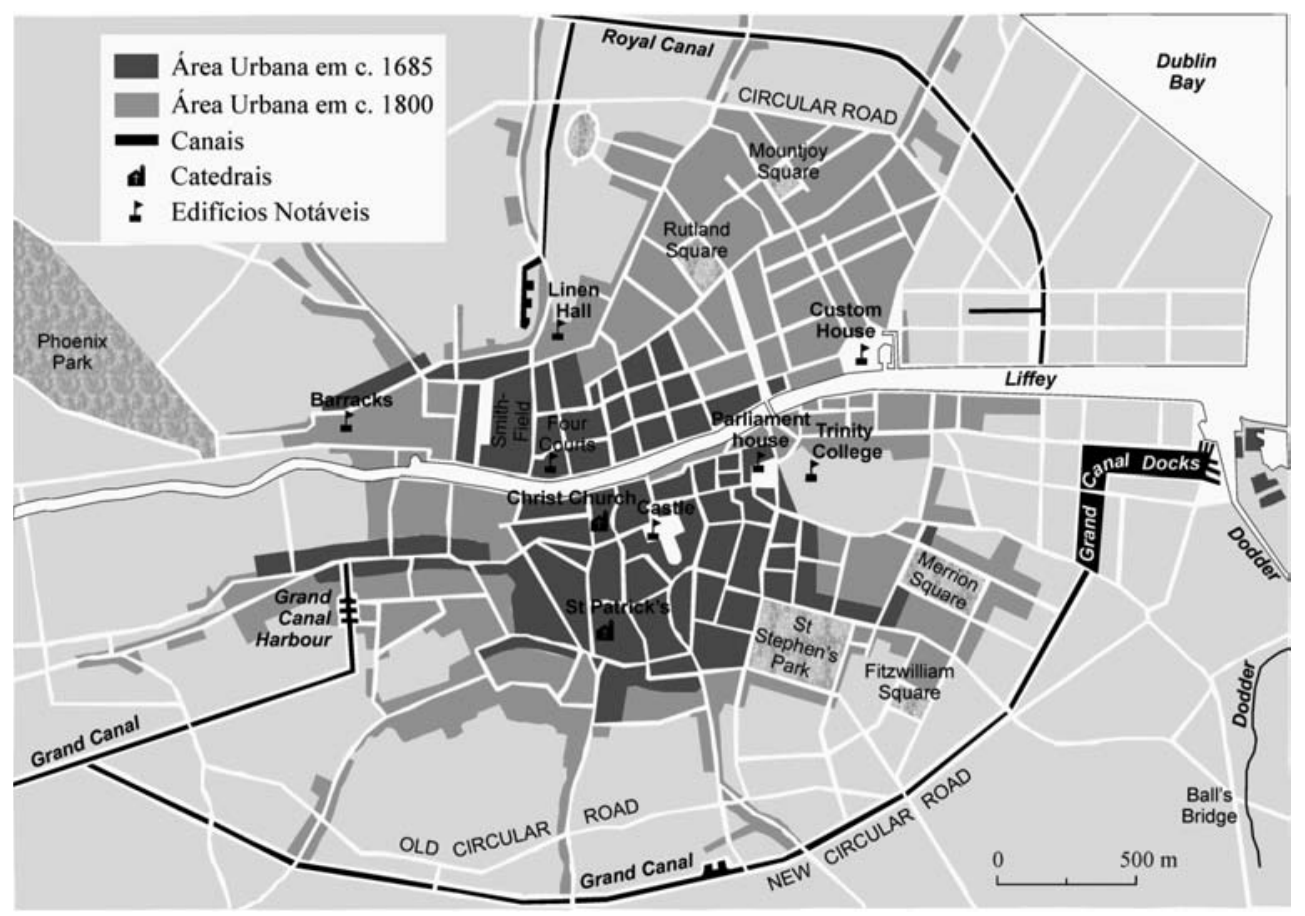

Fig. 2 - O crescimento de Dublim até ao século XIX

Fig. 2 - The growth of Dublin until the $19^{\text {th }}$ century

Fonte: adaptado de DuFFy (2000)

Porém, mais que o século XVII, foi o século XVIII que marcou definitivamente a feição de Dublim. A elite anglicana, detentora da terra e do capital económico e cultural, 
que saíra vitoriosa dos conflitos do século XVII, procurou impor e afirmar o seu poderio político e simbólico sobre a maioria católica também através da paisagem: «[...] at both local and national levels the ruling elite assiduously sought to remould both the rural and urban landscapes in the Anglican image they held dear» (DuFFy, 2000: 78). Assim, tal como no campo se edificam grandes palácios em estilo neoclássico, enquadrados por magníficos jardins, nas cidades operam-se importantes reformas urbanísticas. Dublim, que dispunha de parlamento provincial, com câmara de lordes e comuns, e constituía, por conseguinte, o lugar de afirmação por excelência dessa mesma elite, recebe uma especial atenção, expandindo-se e modernizando-se. Em 1757, é criada pelo parlamento a Wide Streets Comission, uma das primeiras autoridades para o planeamento urbano de toda a Europa; por sua iniciativa se fariam profundas reformas urbanísticas na cidade existente, tendo em vista corrigir e adequar o traçado das ruas à nova estética neoclássica. Promotores imobiliários privados procederiam, por sua vez, segundo planos bastante rigorosos, à urbanização de extensas áreas. Uma dessas operações foi a que o financeiro Luke Gardiner iniciou em 1714 na margem norte do Liffey, dela vindo a resultar a ocupação de todo o espaço em redor da actual O'Connell Street, até à Gardiner Street. De 1762 é o plano da Merrion Square, tida hoje como um dos melhores exemplos do urbanismo e arquitectura georgianos.

O século XVIII terminaria da pior forma para a capital irlandesa. Na sequência da fracassada rebelião de 1798, inspirada pelas revoluções francesa e americana, o poder britânico endureceu a sua autoridade na ilha, decidindo suprimir o parlamento provincial e limitar a autonomia da Irlanda. Parte significativa da elite política e económica migrou então para a Inglaterra, com efeitos na redução do volume de investimentos. A indústria definhou e a crise rural agudizou-se. Nas cidades, particularmente em Dublim, a consequência do abandono das grandes casas georgianas foi um súbito excesso de oferta de habitação no mercado imobiliário e a queda das rendas. O agravamento das condições de vida no campo, que atingiu a sua máxima gravidade durante a Grande Fome, em 1845-46, teve como efeito, para além do aumento da mortalidade, o êxodo rural, primeiro que tudo com a emigração para a América, mas também, como opção de recurso, com a fuga para Dublim. Justamente por isso, de todos os condados da Irlanda, este seria o único a registar ganhos de população entre 1841 e 1851.

Este crescimento da população dublinense, que prosseguiu pelo século XIX, não seria acompanhado por produção de habitação compatível, nem em quantidade, nem em qualidade. $\mathrm{O}$ resultado foi a degradação das condições de habitação na cidade consolidada e a insalubridade, generalizando-se como solução a subdivisão e partilha de antigas mansões por várias famílias e a sobrelotação dos fogos. A perpetuação no tempo dessas situações explica que muito do esforço realizado pelas autoridades no centro de Dublim ao longo do século XX, praticamente desde a independência aos anos 60 , tenha tido por objectivo quase só corrigir esses problemas, procedendo a operações de slum clearance e ao realojamento das populações em áreas periféricas de baixa densidade, em bairros inspirados no modelo da 'cidade-jardim'. De resto, em boa verdade, nem mesmo esse esforço terá sido grande: a cidade «[...] was considered by many to be an emblem of the colonial past, ultimately not valued by an essentially agrarian society» (TYNAN, 1997: 118), disso resultando que os problemas urbanos não tivessem sido, até aos anos 70 , entendidos como uma prioridade da política irlandesa. 


\section{A EXPERIÊNCIA DE REABILITAÇÃO DE TEMPLE BAR}

Uma das áreas mais críticas do centro de Dublim foi, até datas muito recentes, Temple Bar, bairro a que já aludimos e se estende, no sentido norte-sul, do Liffey à Dame Street, e, no sentido leste-oeste, entre o Bank of Ireland e a Christ Church Cathedral (fig. 3). Noutros sectores do centro da cidade, a situação nunca chegou a ser tão dramática. O espaço a sudeste, em torno da Merrion Square, por exemplo, graças à sua original vocação aristocrática, traduzida numa superior qualidade arquitectónica dos edifícios, e também à proximidade de elementos nobilitadores, como a universidade, vários grandes equipamentos culturais (National Gallery, National Museum, National Library, Royal Hibernian Academy, etc.), e jardins (St. Stephen's Green, Merrion Square, Fitzwilliam Square), evoluiu no sentido de uma intensa terciarização, vindo a captar, ao longo do século XX, os serviços, públicos e privados, mais importantes, e também o comércio mais raro. Evolução algo semelhante tivera o sector a nordeste, correspondente à área urbanizada por Gardiner, a início vocacionada para área residencial da burguesia industrial, comercial e de liberais. Temple Bar, todavia, pela sua ligação mais estreita à vida portuária, seguira um caminho diferente, especializando-se na armazenagem e na pequena indústria, nas actividades nocturnas (teatros, bordéis, pubs), e na oferta de habitação para as classes populares.

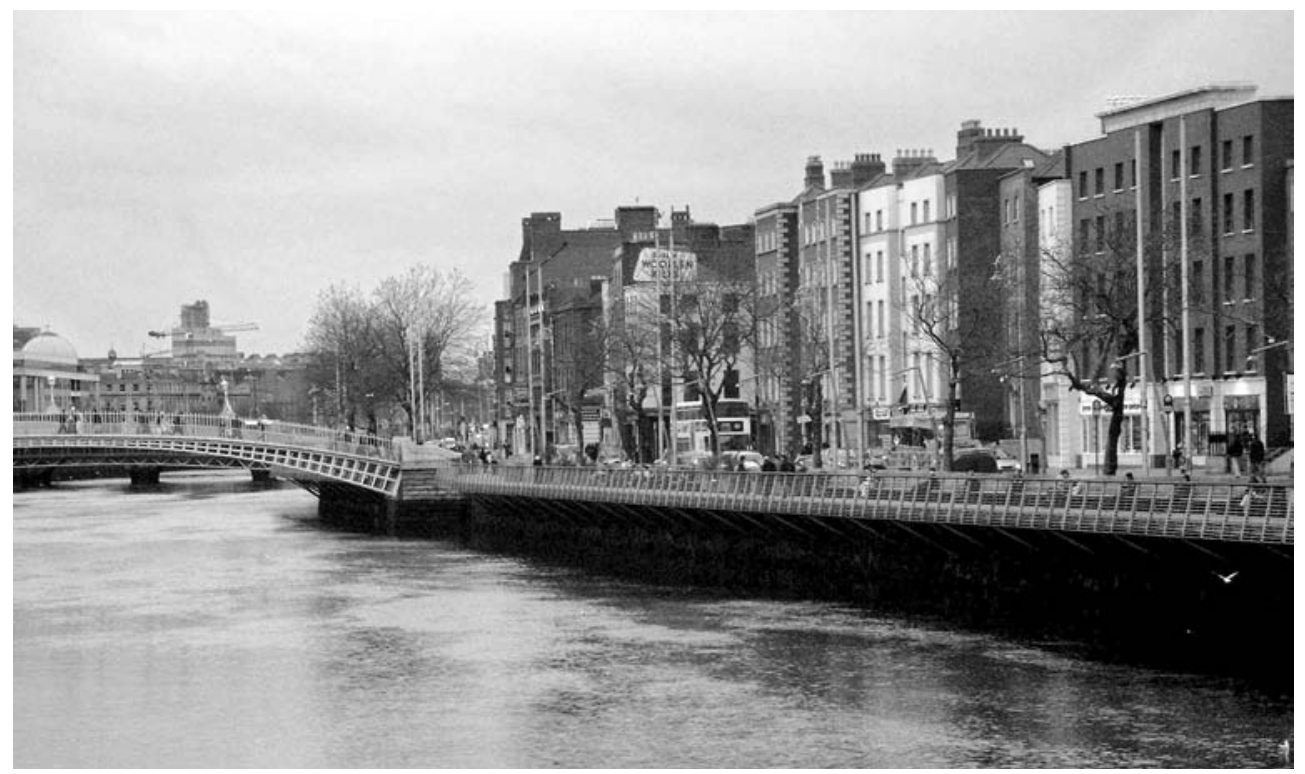

Fig. 3 - Temple Bar visto do Liffey

Fig. 3 - Temple Bar seen from the Liffey

Em meados do século XX, estas tradicionais funções entraram em rápida decadência e Temple Bar foi sendo abandonado. A expansão das infra-estruturas portuárias para jusante impeliu à migração da armazenagem. As oficinas e as pequenas fábricas foram igualmente desaparecendo, ou por cessação da actividade, ou por deslocalização 
para áreas mais periféricas, o que também acabou sucedendo com a população. De resto, desde os anos 70 que a CIÈ, companhia nacional de transportes rodoviários irlandesa, tinha a intenção de construir na área de Temple Bar uma grande estação de autocarros, integrada numa estratégia mais ampla de modernização do sistema de transportes de Dublim, o que, prevendo a demolição de extensa parte do bairro, acelerou o seu despovoamento.

A conjuntura económica desfavorável dos anos 70 foi obrigando a CIÈ a adiar sucessivamente a concretização desse projecto. Enquanto aguardava, a companhia opta por ir colocando no mercado, sob a forma de arrendamento a baixo custo, o património que entretanto fora adquirindo em Temple Bar e que tenciona vir a ocupar com a nova estação. "These temporary leases and very low rents attracted fringe and alternative activities and businesses - often owned by young people - that would probably not have been able to exist elsewhere in the city» (TIESDALl et al., 1996: 90). Graças a isso, aos poucos, ateliês de artistas, gráficas, lojas de roupa e discos em segunda mão, oficinas de artesãos urbanos e algumas pequenas associações, começam a instalar-se no bairro.

Seriam estes actores a protagonizar a mudança em Temple Bar e a abrir caminho à sua reabilitação. «These people and those they attract often follow a particular lifestyle where work and ideas and friendships are pursued in bars, restaurants, clubs, venues, galleries and other semi-public meeting places... they are also a terrain or environment in which new ideas, new products and new opportunities can be explored, discussed, tried and tested»(Montgomery, 1995: 135). Estavam portanto criadas condições para que entre esses novos 'residentes', aos quais depois, por difusão, se solidarizaram outros artistas, intelectuais e arquitectos, ainda que sem especial relação com o local, começassem a surgir críticas ao velho plano da CIÈ e passassem a ser equacionadas alternativas para o futuro de Temple Bar.

A constituição em 1988 do Temple Bar Development Council (TBDC), como grupo organizado onde se reuniram os novos actores com interesses no bairro e outros críticos da opção da CIÈ, representa um momento essencial na história da revitalização de Temple Bar. O TBDC funcionaria como lobby junto do governo local e nacional em favor da valorização do património histórico e arquitectónico dessa área do centro de Dublim e da dinamização local do turismo e das actividades culturais. Num ambiente de preparação da iniciativa 'Cidade Europeia da Cultura', programada para decorrer em Dublim em 1991, as ideias defendidas pelo TBDC acabariam por ter acolhimento junto das autoridades, nomeadamente do governo central, vindo o projecto da CIÈ a ser definitivamente abandonado em 1990 e substituído pela ideia de transformar Temple Bar no 'bairro cultural' da capital irlandesa.

Para prosseguir este novo objectivo, o governo promulga em 1991 a Temple Bar Area Renewal and Development Act, que vem estabelecer um conjunto de incentivos financeiros destinados a atrair empresas para o bairro e investimentos privados para a reabilitação e renovação dos edifícios situados nos 14 hectares que, da Westmoreland Street à Fishamble Street, se estendem entre os cais e a Dame Street. Quase em simultâneo, cria a Temple Bar Properties Ltd. (TBP), empresa privada de capitais maioritariamente públicos, inspirada no modelo das 'sociedades de desenvolvimento urbano' britânicas - as urban development corporations -, e que viria a ser um elemento essencial na recuperação, renovação e revitalização de Temple Bar.

Através da aquisição de terrenos e edifícios da CIÈ, a TBP tornou-se rapidamente no principal proprietário imobiliário de Temple Bar. Essa forte concentração de solo e imóveis nas mãos de um único proprietário viria, de resto, a ser uma das razões para o sucesso da experiência de reabilitação de Temple Bar. Outra, o facto da TBP ter juntado 
a essa sua responsabilidade directa na gestão e valorização do património imobiliário, um envolvimento activo na revitalização funcional do bairro, que prosseguiu mesmo depois de 2001 e de ter sido dado por concluído o plano de reabilitação arquitectónica e urbanística; manter e aprofundar o desenvolvimento de Temple Bar como 'bairro cultural' de Dublim passou desde então a ser a missão da TBP, que, operando como uma instituição sem fins lucrativos, está obrigada a reinvestir as receitas que obtém do imobiliário na conservação e animação dos espaços públicos do bairro, no funcionamento e programação dos centros culturais nele existentes, na manutenção da oferta de espaços, a baixo custo, para artistas e empresas do sector cultural, e, em termos mais gerais, na promoção da imagem de Temple Bar.

A reabilitação arquitectónica e urbanística de Temple Bar seguiu as orientações de um plano estratégico definido em 1991 - o Temple Bar Framework Plan -, surgido de um concurso internacional promovido pela TBP. Entre os seus objectivos essenciais, o referido plano elegia a combinação da «[...] regeneration of a resident population in Temple Bar, consolidation of its existing character, conservation of the urban fabric and the integration of renewal proposals» (TBP, 1991: 16).

A recuperação de uma comunidade residente para Temple Bar, em cuja área total residiriam, em 1991, duas escassas centenas de habitantes, foi considerada pelo plano como uma prioridade (fig. 4). Pretendia-se sobretudo que se tratasse de uma comunidade socialmente diversificada, onde estivesse igualmente presente população jovem e mais idosa, estudantes e activos, isolados e famílias. Para tal, propunha-se, e viria a ser

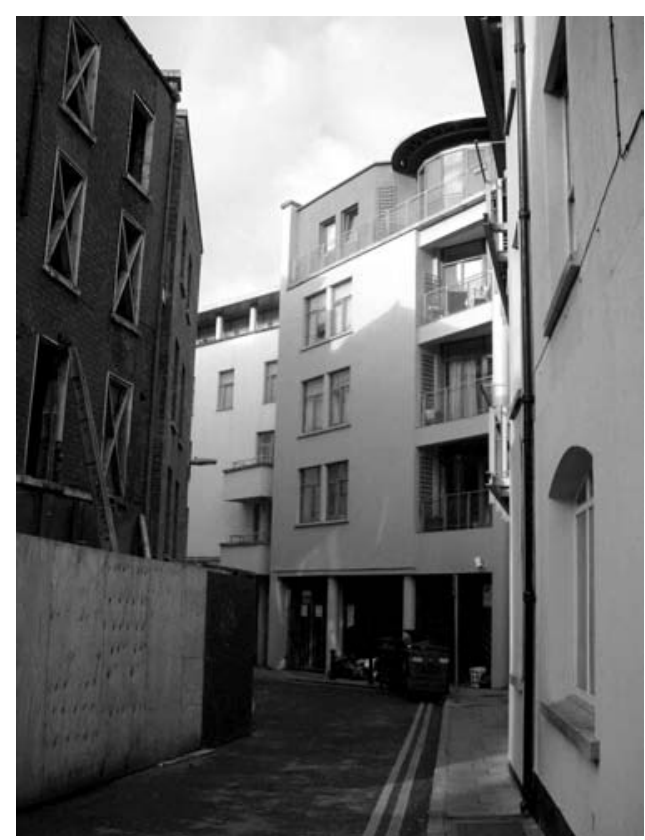

Fig. 4 - O programa residencial de Temple

Bar: novos edifícios em Exchange St.

Fig. 4 - Temple Bar's residential programme: new buildings on Exchange St. concretizada, "A diverse range of residential opportunities - student housing, family apartments, artist's studios, hostels and hotels [...]» (ibid.: 28).

Em articulação com a recuperação da função residencial, apareciam depois os objectivos da dinamização e diversificação dos usos, numa lógica de recuperação e enriquecimento da 'vida de bairro', e o cuidado com a conservação do património. LOTS (Living Over The Shops) foi o conceito urbano que se procurou aplicar em Temple Bar (fig 5). Do ponto de vista do património arquitectónico e da paisagem, embora o plano considerasse que a demolição deveria ser uma medida excepcional e a conservação dos edifícios a norma, não deixava de referir o dever de se enriquecer o «Existing range of architectural styles [...] by encouraging exemplary modern infill buildings, carefully scaled to their contexts» (ibid.: 29) (figs. 6 e 7).

O plano, finalmente, conferiu também grande atenção aos espaços públicos e à circulação. Para além de preconizar uma valorização urbanística do principal eixo longitudinal de Temple Bar e a sua 


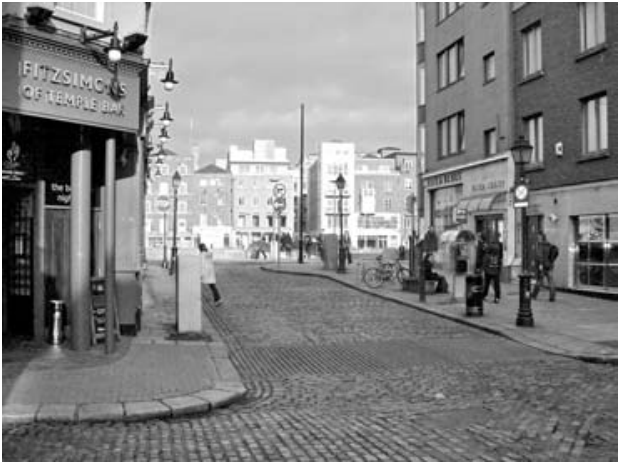

Fig. 5 - A aplicação do conceito LOTS em Temple Bar

Fig. 5 - The application of the LOTS concept in Temple Bar

pedonalização, potenciando-o como elemento vertebrador da vida do bairro e como factor de coesão e identidade, sustentava ainda a necessidade de aumentar a permeabilidade de Temple Bar, tanto interna como externa. Para tal, eram propostas operações de renovação pontuais, com impactes na morfologia urbana, designadamente através da abertura de

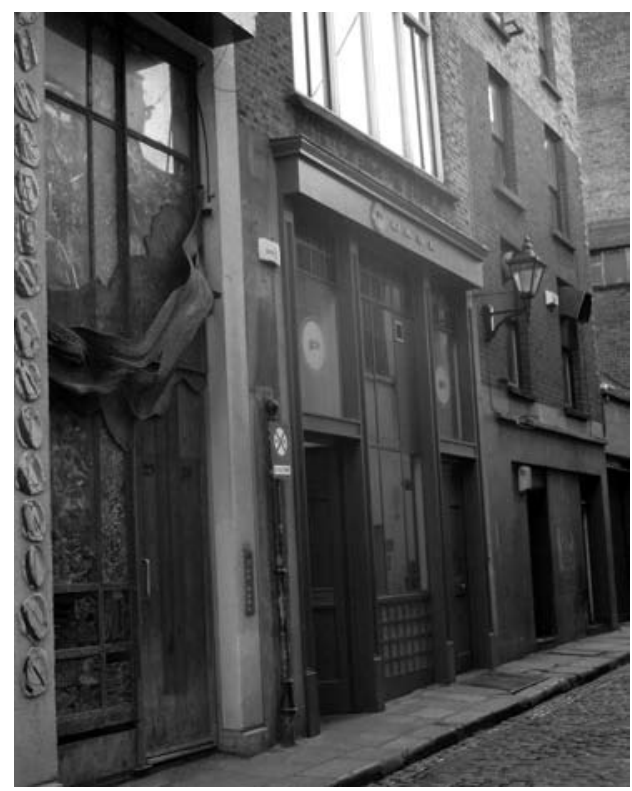

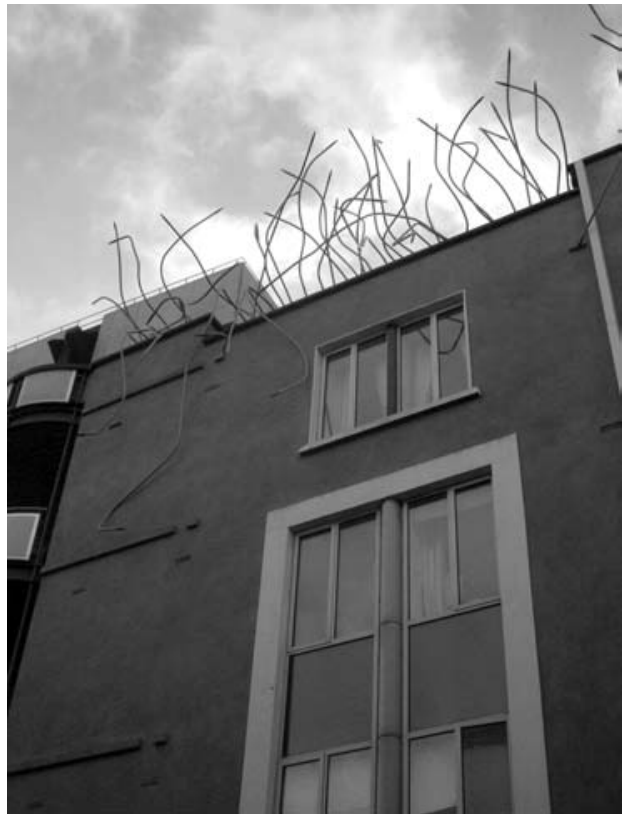

Fig. 6 - Exemplo de renovação urbana em Cecilia St., Temple Bar

(notar o detalhe artístico na cobertura)

Fig. 6 - Example of urban renovation on Cecilia St., Temple Bar

(note the artistic detail on the roof)

pequenas ruas e passagens entre os edifícios. Articulada com estas, aparecia a intenção de criar, nomeadamente em lotes desocupados ou com construções de fraca qualidade, novas praças e espaços públicos que pudessem vir a ser associados a funções com um efeito de íman e capacidade de gerar vida urbana (fig. 8).

A reabilitação física de Temple Bar, norteada pelo Temple Bar Framework Plan, a cujas linhas gerais anteriormente alu-

Fig. 7 - Exemplo de reabilitação urbana criativa em Eustace St., Temple Bar (notar o detalhe artístico na fachada)

Fig. 7 - Example of creative urban rehabilitation on Eustace St., Temple Bar (note the artistic detail on facade) 
dimos, seria acompanhada e complementada por um programa de desenvolvimento integrado destinado à revitalização do bairro-o Development Programme for Temple Bar. Para a concretização desse programa viriam a concorrer não só fundos públicos irlande-ses, nomeadamente do governo central, mas também comunitários, através do apoio previsto pela Comissão Europeia para projec-tos urbanos inovadores (artigo 10. ${ }^{\circ}$ do FEDER).

O programa de desenvolvimento organizava-se em cinco eixos ou sub-programas. $\mathrm{O}$ primeiro, a que correspondeu a maior fatia dos investimentos públicos, foi consagrado ao sector cultural. Assumindo-se que a economia da cultura deveria ser a nova principal especialização de Temple Bar, procuraram-se consolidar os usos a ela relativos e dinamizar a vida cultural do bairro (figs. 9, 10 e 11). Para além da cria-ção de novos equipamentos e instituições de interesse artístico, sobretudo - embora não exclusivamente - nas áreas do audiovisual, multimedia e artes gráficas (DESIGNyard, ArtHouse, Gaiety School of Acting, DIT

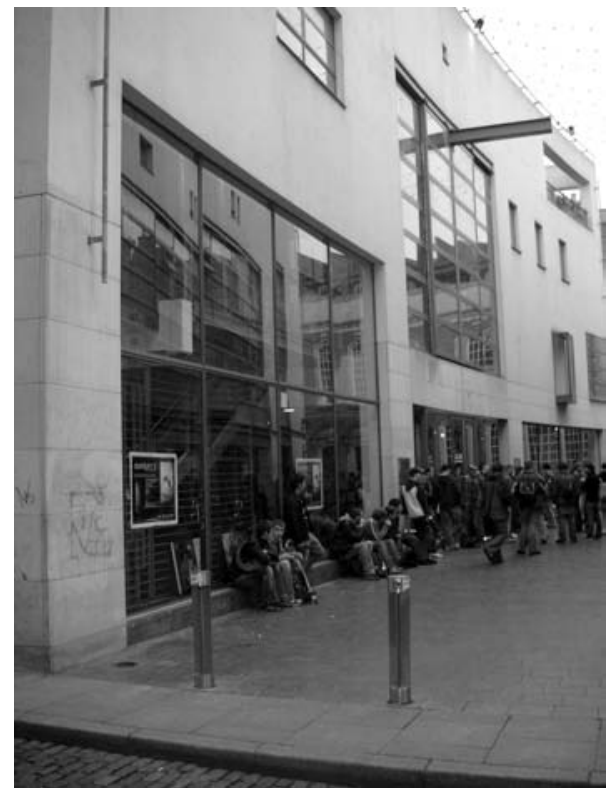

Fig. 8 - Intervenções na morfologia urbana: Curved St., Temple Bar

Fig. 8 - Changes in urban morphology: Curved St., Temple Bar School of Photography, Temple Lane Studios, Black Church Print Studio, Irish Film Centre, etc.), foi também dada grande atenção nesse programa cultural às acções de natureza imaterial, como seja o apoio à realização de cursos de formação e treino de artistas, à programação dos centros culturais entretanto instalados em Temple Bar, e à promoção da sua actividade. Seria esta, de resto, a componente do programa de revitalização do bairro considerada mais inovadora pela Comissão Europeia, vindo a beneficiar de financiamento comunitário ao abrigo dos já referidos fundos do FEDER para os Projectos Pilotos Urbanos.

Um segundo sub-programa foi dedicado ao sector residencial, o que aparece em concordância com a prioridade dada à recuperação demográfica. Embora se tenha procurado privilegiar, sempre que possível, o restauro dos edifícios, recuperando antigos fogos e adaptando para uso residencial velhos imóveis inicialmente destinados a outros fins, não se renunciou à produção de habitação em novas construções. Na primeira fase de implementação do programa, entre 1991 e 1996, coube, só a esta última componente, $43 \%$ do total de alojamentos colocados no mercado. Na segunda fase, que correspondeu ao período de 1996 a 1999, os novos empreendimentos ocuparam um lugar ainda mais importante, sendo quase inteiramente nesses moldes que se procedeu ao desenvolvimento da área residencial a oeste da Parliament Street, onde foi criada habitação para cerca de 700 pessoas.

Apostar numa oferta de habitação diversificada foi uma das preocupações do programa residencial proposto e seguido em Temple Bar. Para além de tipologias residenciais variadas (do estúdio ao apartamento familiar de dimensão média - T3), houve o cuidado em oferecer habitação para diferentes segmentos socioeconómicos. Na primeira 


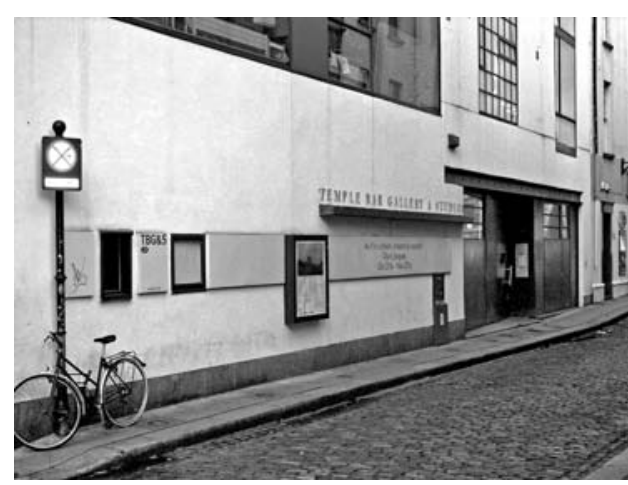

Fig. 9 - A aposta em Temple Bar como 'bairro cultural': estúdios para artistas

Fig. 9 - Investment in Temple Bar as a cultural quarter: studios for artists

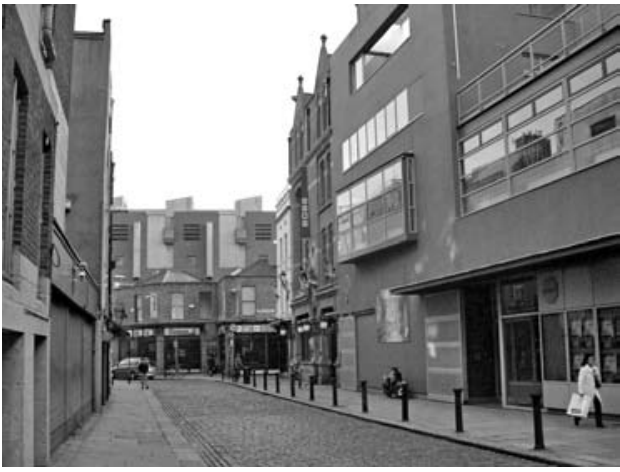

Fig. 10 - A aposta em Temple Bar como 'bairro cultural':

o New Theatre (primeiro edifício à direita)

Fig. 10 - Investment in Temple Bar as a cultural quarter: the New Theatre (first building on the right)

fase do programa, por exemplo, uma parte da habitação produzida destinou-se a residências universitárias. $30 \%$ dos fogos construídos na segunda fase correspondeu a habitação social, promovida em parceria pela TBP e as autoridades municipais.

Para a intervenção da TBP no sector imobiliário foi essencial o recurso aos fundos do Banco Europeu de Investimentos. Esperava-se que a venda de alojamentos e o arrendamento das lojas nos empreendimentos entretanto desenvolvidos pudessem vir a cobrir os custos do empréstimo. Por outro lado, graças aos incentivos financeiros que a lei de 1991 veio criar, foi também possível captar importantes investimentos privados para o programa residencial.

O sucesso deste programa, volvida mais de uma década sobre o seu arranque, é patente. A recuperação demográfica, tantas vezes anunciada como objectivo prioritário nos planos de reabilitação de centros históricos, e, todavia, quase sempre fracassada, conseguiu em Temple Bar cumprir-se: graças às opções tomadas em matéria de habitação, a população residente nos 14 hectares intervencionados aumentou em mais de dez vezes desde 1991, estimando-se que em 2003 ascendesse já a mais de 2500 residentes.

A terceira componente da estratégia de revitalização de Temple Bar consistiu na dinamização do comércio. Para tal, a TBP não se limitou a assegurar que fossem oferecidos espaços para comércio ou restauração nos pisos térreos dos edifícios. Desenvolveu para além disso uma eficaz acção de marketing junto de potenciais investidores com o intuito de chamar a atenção para as oportunidades de negócios existentes em Temple Bar, e procurou gerir com visão estratégica e coordenada a instalação dos novos estabelecimentos, em moldes algo comparáveis aos que se seguem nos centros comerciais. A selecção dos investimentos foi feita de forma criteriosa, de modo a garantir uma oferta de comércio e serviços diversificada e complementar, quer relativamente à habitação, quer ao cluster cultural.

A par dos programas cultural, residencial e comercial, e com eles articulado, foi ainda considerado um quarto eixo de acção especificamente destinado ao marketing. A promoção da imagem de Temple Bar foi sempre tida como um aspecto essencial na estra- 


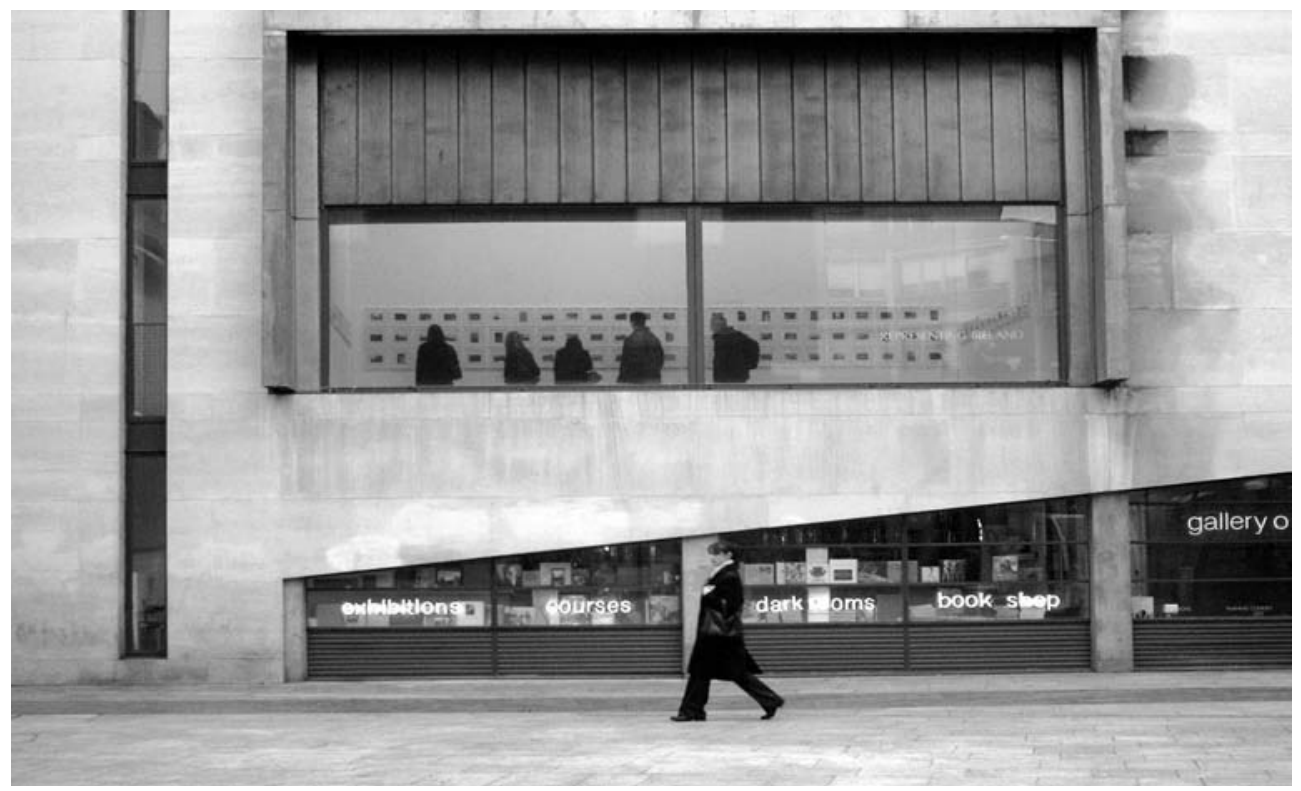

Fig. 11 - A aposta em Temple Bar como «bairro cultural»: uma galeria de arte (especializada em fotografia)

Fig. 11 - The investment in Temple Bar as a cultural quarter: an art gallery (specialized in photography)

tégia de revitalização do bairro. A prioridade consistiu em criar e consolidar uma identidade forte em torno da marca Temple Bar, capaz de a tornar facilmente reconhecida pela população em geral e num sinónimo de modernidade, irreverência e cosmopolitismo. Entre as medidas desenvolvidas com esse intuito, é de destacar a criação de um centro de informação destinado a potenciais investidores, residentes e visitantes, a realização de campanhas de publicidade nos media, e a aposta na animação de rua e na programação cultural.

A preocupação ambiental constituiu o fundamento do último eixo da estratégia integrada de revitalização de Temple Bar. Assumindo-se que a desejada valorização deste espaço como 'bairro cultural' de Dublim e como nova área residencial e de comércio, atractiva para dublinenses e turistas, pressupunha um grande cuidado com a imagem e com o quadro de vida urbano, foi definido no Development Programme for Temple Bar um quinto sub-programa para o melhoramento do ambiente. A maior parte das medidas desenvolvidas no âmbito deste eixo visou sobretudo a salvaguarda e valorização do património (incluindo a componente arqueológica) e a qualificação dos espaços públicos, aqui se contemplando deste a abertura de novas praças e ruas à repavimentação das já existentes, à modernização e ocultação das redes de infra-estruturas, à renovação e qualificação do mobiliário urbano, e à implementação de um novo plano de tráfego (fig. 12). Grande atenção foi também dada à segurança pública, tendo em vista ultrapassar uma certa imagem negativa que o bairro possuía neste capítulo; assim, em colaboração com o ministério da justiça e a polícia, a TBP desenvolveu e implementou 


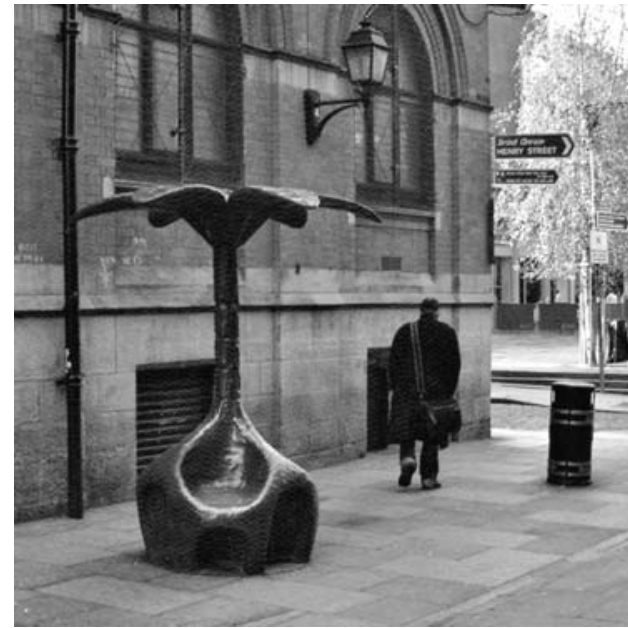

Fig. 12 - Um exemplo da valorização de Temple Bar através do mobiliário urbano

Fig. 12 - An example of Temple Bar's enhancement, via the urban furniture um plano de segurança que incluiu, entre outras medidas, a instalação de um sistema de videovigilância nas ruas e a criação de um corpo de segurança local.

A coordenação dos esforços na qualificação do ambiente urbano, no marketing e na promoção da imagem do bairro, e depois na criação de condições infraestruturais e de organização favoráveis ao desenvolvimento de novas actividades vocacionadas para a cultura, o lazer e o consumo, traduziu-se em resultados que justamente se podem considerar positivos. A tão desejada ambição de transformar Temple Bar no 'bairro cultural' de Dublim foi conseguida. Nessa área limitada da cidade, operavam em 2004 mais de cinquenta organizações do sector cultural, entre ateliês e associações de artistas, estúdios de cinema e de gravação, escolas de artes, centros culturais, galerias, teatros, etc. Dessa forte concentração de actividades culturais resultou a forma-ção

de um ambiente vibrante que acabou por atrair empresas de outros sectores, em particular estabelecimentos vocacionados para o lazer, a restauração e o consumo de bens superiores: ao todo, o número de empresas localizadas em Temple Bar ultrapassava em 2004, segundo a TBP, as quatro centenas, mais de metade das quais corresponderiam a actividades ainda de algum modo relacionadas com a cul-tura e o lazer (hotéis, pubs, restaurantes, lojas de moda, antiquários, design e decoração, etc.).

\section{REMATE}

Temple Bar é justamente considerada uma das experiências mais bem sucedidas de reabilitação de centros históricos em toda a Europa. Em pouco mais de uma década, foi possível recuperar população, inverter uma situação de exclusão social que era a princípio muito marcada, trazer novas funções para o bairro, criar emprego e valorizar o ambiente urbano. É também frequentemente apontada como uma experiência inovadora pelo destaque que a fileira da cultura teve na estratégia de revitalização prosseguida.

A razão do sucesso de Temple Bar não reside apenas nesta última opção, embora tal aposta nas indústrias culturais tenha seguramente pesado, a crer no papel que a fileira da cultura tem hoje nas economias urbanas e no quanto pode contribuir para a recuperação de áreas em crise (BRITo HenRIQues, 2000). Talvez mais importante que isso tenha sido o facto de se ter sabido pensar para o bairro em causa um projecto claro e mobilizador, que no caso vertente foi a afirmação de Temple Bar como 'bairro cultural' de Dublim. Em torno desse projecto, estruturou-se um programa de acção que, contemplando diferentes domínios (criação de equipamentos, marketing, imagem e ambiente urbano, habitação, etc.), obedeceu a uma orientação de conjunto e foi pensado de forma integrada, com medidas articuladas entre si que concorriam para o objectivo geral defi- 
nido e acabaram por substanciar uma visão estratégica forte e coerente. Esta coragem em assumir uma ideia clara para o bairro e de apostar numa especialização marcada em torno da cultura e do entretenimento em geral não deixa, todavia, de envolver alguns perigos: o de transformar Temple Bar numa 'bolha turística' isolada na demais cidade é o mais evidente; outro, o de levar a uma certa carnavalização ou 'disneycização' da paisagem urbana do bairro.

A articulação e complementaridade entre acções destinadas à valorização física (arquitectónica e urbanística) e à revitalização demográfica e funcional é outro factor que deve ser apontado no diagnóstico das causas do sucesso da operação desenvolvida em Temple Bar. A reabilitação urbana deve envolver sempre essas duas dimensões de actuação, com acções simultâneas e concertadas. Numa análise de maior detalhe, merecem depois atenção as opções concretas que se tomaram em Temple Bar no capítulo da reabilitação física, já que delas terá dependido muito do sucesso da operação, nomeadamente no que respeita à recuperação demográfica e à valorização do ambiente urbano; em Temple Bar, contrariamente ao que sucede na maioria dos centros históricos, não se rejeitou a renovação urbana - ainda que harmonizada -, com demolições e construção de novos imóveis, alterações na planta (abertura de novas ruas e praças) e transformações no próprio cadastro urbano (emparcelamento).

Do ponto de vista da governança, a experiência de Temple Bar também fornece lições úteis. Primeiro, sublinha as vantagens da concentração fundiária, uma vez que a existência de um grande proprietário, ademais público, parece, no caso vertente, ter sido decisivo para o sucesso da operação de reabilitação. Depois, mostra as vantagens que há em existir uma autoridade ou instituição responsável pela coordenação e implementação do programa de revitalização, nos seus vários eixos, tal como, em termos mais gerais, pela gestão integrada da área a reabilitar (nas várias dimensões da habitação, do comércio, dos equipamentos, dos espaços públicos, etc.). Talvez não fosse indispensável tratar-se, como sucedeu em Temple Bar, de uma sociedade privada; bem mais determinante que a natureza jurídica da instituição responsável por essa gestão será o conjunto de competências que se lhe atribuem e o papel de que fica incumbida. Por último, a experiência de Temple Bar recorda ainda como, não obstante o grande entusiasmo que hoje parece existir em relação às novas formas de parceria público-privado e às potencialidades do mercado, o investimento público continua a ser, apesar de tudo, indispensável, nomeadamente quando se trata de criar equipamentos, intervir na qualificação dos espaços públicos, e fazer, em termos mais gerais, a gestão da imagem do bairro.

Não seria correcto, finalmente, deixar de notar que o sucesso da experiência de Temple Bar se terá devido também, pelo menos em parte, a factores que se não prendem directamente com o local nem com as opções específicas nele tomadas. O maior ou menor sucesso da reabilitação urbana depende sempre em parte - como já antes defendemos - de variáveis externas, mostrando-se nomeadamente ser difícil, senão impossível, «[...] promover uma plena reabilitação dos núcleos antigos das cidades em condições contextuais adversas, nomeadamente, em cenários demográficos e económicos recessivos»(BRIto HenRIQues, 2003: 543). Nessas condições, a capacidade de resposta dos privados aos estímulos dados pelas políticas públicas fica necessariamente diminuída. A experiência de Temple Bar terá beneficiado precisamente da situação contrária, uma vez que se dá num contexto francamente favorável: entre 1991 e 2002, a população irlandesa aumentou $11 \%$ em resultado de um crescimento natural e de um saldo migratório positivos, sendo que a região de Dublim foi precisamente das que mais beneficiou desse crescimento. Do ponto de vista económico, o progresso foi ainda mais notável: a Irlanda cresceu ao longo dos anos 90 sempre muito acima da média da UE 15, com crescimentos do PIB que em vários anos foram superiores a $8 \%$. 


\section{BIBLIOGRAFIA}

Brito HenRiques, E. (2000) - O sector económico da cultura na Área Metropolitana de Lisboa. Aspectos locativos e implicações nas políticas urbanas. Finisterra-Revista Portuguesa de Geografia, XXXV (69): 109-136.

Brito Henriques, E. (2003) - Cultura e território, das políticas às intervenções. Estudo geográfico do património histórico-arquitectónico e da sua salvaguarda. Tese de doutoramento em Geografia Humana. Faculdade de Letras da Universidade de Lisboa, Lisboa (mimeo.).

CHOAY, F. (1992) - L'allégorie du patrimoine. Seuil, Paris.

Duffy, S. (2000) (ed.) - Atlas of Irish history. Gil \& Macmillan, Dublin.

Gowen, M. (1996) - The historical origins of Temple Bar. In AAVV - Temple Bar. The power of an idea. Temple Bar Properties, Dublin: 21-15.

LARKham, P. (1996) - Conservation and the city. Routledge, London \& New York.

Montgomery, J. (1995) - The story of Temple Bar: creating Dublin's cultural quarter. Planning Practice and Research, 10 (2): 135-172.

Orbașli, A. (2000) - Tourists in historic towns. Urban conservation and heritage management. E. \& F. N. Spon, London \& New York.

TPB (1991) - Temple Bar lives! Winning architectural framework plan. Temple Bar Properties, Dublin.

Tiesdall, S.; Oc, T.; Heath, T. (1996) - Revitalizing historic urban quarters. Architectural Press, Oxford MA. \& London.

TynAN, D. (1997) - The culture of the city - Temple Bar, Dublin, and the emergence of a post-colonial identity. In AAVV - La ciutat històrica dins la ciutat. Universitat de Girona, Girona.

URban TASK Force (1999) - Towards an urban renaissance. Spon Press, London. 